\title{
Gender Disparity and Cultural Impacts on Girls' Education in Laos
}

\author{
INLEUSA BASENGKHAM \\ University of Minho, Portugal
}

\begin{abstract}
This study aims to understand the problem of school dropouts in Houa Kham village, a rural district of Savannakhet Province, Laos. The main objective is to understand the reason why some school-age children dropout of school before finishing the primary level. Qualitative research techniques were applied; participant observation and interviews were conducted with village authorities, school principals, teachers, and the community as well as the parents of four families. The investigation used four main research dimensions, family financial situation, cultural and traditional beliefs, gender roles, and the current situation of education. The results of the study revealed that cultural beliefs and gender disparity within the community seem to be the major factors associated with dropping out of school. Some policy intervention for future development and strategic plans to improve the quality of education in rural areas of Laos were addressed to the Government of Laos (GOL) to respond to this crucial problem.
\end{abstract}

\section{Keywords}

gender disparity, cultural belief, school dropout, primary education, Laos

\section{Introduction}

Gender equality does not necessarily mean equality of outcomes for males and females. In the Development Report of the World Bank in 2006, gender equality is defined as "equal access to opportunities that allow people to pursue a life of their own choosing and to avoid extreme deprivation in outcomes" - that is, gender equality in rights, resources, and voice (World Bank 2007).

According to the World Bank, equality of rights refers to equality under the law, whether customary or statutory, while equality of resources refers to equality of opportunity, including equality of access to human capital investments and other productive resources and access to the markets. Equality of voice captures the ability to influence and contribute to the political discourse and the development process (World Bank 2007: 106).

Gender equality in rights, resources and voice surfaces in three different domains: in the household, in the economy, and in society. The evidence of the household suggests that if equality between men and women within the household increases, the allocation of household expenditures changes; for example, there will be a large share of resources devoted to children's education and health. Distribution of household tasks has normally been influenced by inequality of gender within the household; women are always expected to work inside the home, and are usually limited regarding 
decision-making. In the market, the gender inequality is reflected in the unequal access to land, credits, and labour market, and in significantly less access to new production technologies. And in society, the inequality is reflected by fewer women in political positions (2007: 106).

Women in Laos, especially those who reside in more remote locations, experience a certain amount of inequality in terms of gender and social opportunity. This paper argues that cultural and traditional beliefs results in gender inequality in formal education among women in the sampled community, whereas the family's financial condition and inadequate educational system were not considered to be major factors influencing gender inequality in schooling. Religiously, women are believed to be weak and should not take the role of leader. In addition, ritual tasks require more participation from women than from men. When women are being prepared for these religious performances and ceremonies, they ultimately do not have equal opportunity in formal education throughout the courses of their lives. This paper includes five main sections: after the introduction, the literature review is presented. Section three explains the methodology and indicates the research participants. The fourth section presents the empirical data and discussion. The paper concludes in section five with some suggestions for future policy intervention.

\section{Literature Review}

Some parents have seen the importance of education for their children; they have a prior right to choose the education that their children will receive. In developed countries, the attitude of parents toward the educational attainment of their children is deeply profound. Jager and Holm (2007) suggest that parents have a great desire for the educational success of their children; they notice the importance of academic achievement of their children as a means to acquire personal achievement, higher social status and wealth. Webbink, Smits and de Jong (2012) have examined the role of parental involvement on children's academic performance. Clearly the result shows that children's educational performance was better when parents were involved with school activities. Mahamood et al., (2012) found that the involvement of parents in children's education has many positive effects on their learning outcomes. Miedel and Reynolds (2000) claimed that the early involvement of parents in their children's education has had a long-term effect on children's education, reducing grade retention and increasing child's reading proficiency and other academic achievements. Oketch, Mutisya and Sagwe (2012) have also mentioned the benefits of parental involvement in education of children. So, the earlier the involvement of parents the better the education of the children will be. Other studies made clear that lower motivation to support their children's education is the result 
of low income of the household (Nguon 2012; Kazianga 2012; Løken 2010; Shapiro and Tambashe 2001; Acemoglu and Pischke 2001). Most parents in remote areas of Laos are illiterate; they do not have this skill themselves, and thus they do not support and encourage their children to go to school because they think that education is not necessary for them.

Meanwhile, when the family income is low, it leads to the problem of child labour within the household. This is one of the most serious problems among developing countries. 'Trade influences child time allocation in developing countries through its effects on the returns to education, labour demand, and poverty' (Nguon 2012).It seems obvious that one of the glaring issues that has a major impact on children's education is the problem of children's involvement in household responsibilities. The children have to engage in work and help their families to supplement income and survive. In the republic of Yemen, a significant proportion of children are involved in labour. Yemen is one of the developing countries that has a high number of working children and the country with the lowest rate of female participation in primary education in the world (Edmonds, Topalova, and Pavcnik 2009). The studies of Dyer (2007); Admassie, (2003); Duryea and Arends-Kuenning (2003); Dessy and Knowles (2008) have also concluded significant results regarding child labour and their education. Undoubtedly, poverty has been objectively the major problem of children's schooling in poor nations. Kim (2009) argued that child labour remains an enormous challenge to the achievement of the universal primary education in developing countries, including Kenya. Some children combine work and education. For example Holgado et al. (2014); Kruger (2007); Emerson and Souza (2008) examine the effect of birth order on the potential of children to be included in the labour market. They examine the factors that influence families' decision in sending children either to school or to work. Poverty is again considered to be a major problem for children's education in Laos.

In addition, cultural influences also affect children's education, especially girls' education. Colclough, Rose and Tembon (2000) have studied the relationship between poverty, schooling and gender inequality in Guinea and Ethiopia. In China, Sheng (2012) reveals the condition of children's education in a patriarchal society, where the fathers take the role of leaders, and the mothers take a secondary role. The transmission of this cultural capital has a great effect on children's educational attainment in China. There is other evidence that shows the impact of cultural influences on the education of girls. Stephens (2000) conducted research on girls and basic education in Ghana. This study portrays some interesting points about culture relation and child's education. Cultural influence issue is another concern regarding Lao children's schooling as well. 
Based on the literature review, the following research framework has been created to understand the problem of girls' education in the case of Laos.

School drop out

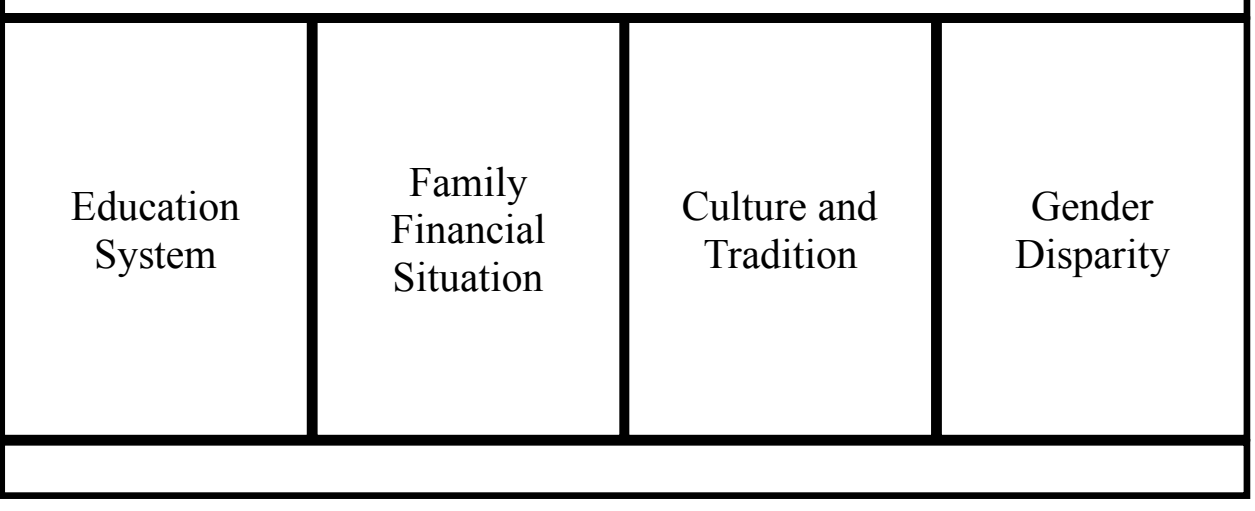

Figure 1: Study Framework

The above framework has been created in order to illustrate the causes of school dropout. As can be seen above, four main factors have been assumed to be the major ones affecting women and girls in rural areas of Laos to leave primary school early. Most families are poor and the parents tend to withdraw their daughters from school after some grades. Also, women in Laos's society are perceived to be weak and should only be followers and this perception also has been one of the major influential factors that cause inequality between sexes. Lastly, the quality of education in rural schools is inadequate. Therefore, these four major causes have been selected to be the main focus of this research study.

\section{Methodology}

Ethnographic research techniques served as an important tool for the data collection in this study. Participant observation and interviews with the village authorities, school principals and teachers and the community have provided valuable insights for the understanding of people's life and historical context of the sampled village.

According to Hammond:

Cultural and social anthropology as a discipline is based on the collection and theoretical analysis of information on nearly every aspect of the various ways life the world's people. Most of this information is collected by the anthropologists working in the field. Anthropological or ethnographic, fieldwork usually involves the careful study at the first hand of the patterned behaviour of the particular human group, the 
family band, a local community, and one or more segment of some larger societal unit, a tribe or a nation. The descriptive account written on the basis of such fieldwork is called ethnography (Hammond 1978: 24).

Ethnography has always been the predominant method in social and cultural anthropology (Hammersley 1992: 11). 'Ethnography in the anthropology was thus designed to be only description or description as a form of argumentation within the well-regulated discourse regimes of culture areas' (Marcus 1997: 54-64). In addition, Spradley considers that ethnography is the work of describing a culture (1979:3).

Besides, Taylor (2002) claimed that ethnography is more appropriate to the study of social world than quantitative methods because ethnographers obtain insiders' view of society to understand other people's own worldviews. Jorgensen (1989) indicated that the most appropriate method to the studies of human assistance is the participant observational approach. Targeted research populations were parents, school principal and teachers, village authorities and elderly people from the community.

\section{Empirical Data and Discussion}

The family's future relies on men; they are strong and are able to cope with many obstacles in the course of their lives in where many of the women are unable to. As young girls, we listen to our parents and do as we are told to do. After marriage, women have to listen to their husbands, be quiet and then are not allowed to take part in some of the important decisions for the household.

The above quote is the elaboration of a woman's perception about gender roles within the community. I had discussed this with some elderly women, having casual conversations with them about women's status and roles in their village. It is clearly shown that most of the women are still trapped in this traditional social norm. This is one of the main issues that impede many young girls in this community from having better opportunities in their lives. The opportunity of being educated; the opportunity to receive equal rights and fulfil their life potential.

Most of the households are poor, and parents are not able to afford their children's school education. People do not have a regular income; there are no paid jobs available in this village. Some grow vegetables as a family business. High proportions of the teenage populations migrate to Thailand where there are more employment opportunities. They drop out of school because of the family financial situation, which reflects a similar situation as that of Brazil; when domestic employment is available to school-age children of the poor households, many of them tend to dropout and enter the labour force in order to produce income for their family (Admassie 2003). 
In Houa Kham village 'going to Thailand has become a traditional way of life among teenagers in this village', said one of the school teachers. It has become the new social trend among teenagers that when they grow up, they have to leave their village in order to search for more opportunities to earn a living as well as help their family's financial stability. Their intentions of going to Thailand are much stronger than their motivations to go to school. The social and cultural environment drives these children to take this decision. Their families, parents and relatives also support them because it is the only way that their lives can be relied on.

When more people move out from their village, they explore other cultures from different societies, so their attitudes sometimes change as they become influenced by these experiences. When they come back to the village, they only have the images of living in a big city, 'the city of light' as it is commonly known amongst the rural population, the images of living in a more modern society. Most people who experienced life in Thailand when they come back to the village they say to those who have never been there, 'get out of the dark and go to see the colourful lights in big cities'. And, as a result of the family's financial situation, parents have to go out to search for food in the forest and keep almost all of the household chores for their children. Income generating activities are another of the major obstacles that hamper children's educational attainment. There is a need for children's labour in all seasons, for example, children's contribution to family tasks is needed when the family grows vegetables. Parents need their children to help water the garden and take care of their vegetables. During rice growing season, parents also need their children to plant their rice, take care of the rice paddy field, and take care of their cows and buffalos to make sure that they do not ruin other people's paddy fields. Children have to work again during the harvesting season. Every task requires children's help, so the question is when can these children go to school?

Despite the fact that people in the community acknowledge the importance of school education, the economic situation of the family forces them to use their children for labour. It is more necessary for the children to work at home to supplement the family income and survival than it is for them to spend their time in school, according to this viewpoint. This attitude is consistent with Jensen and Neilsen (1997), who state that 'poverty forces households to keep their children away from school'. The study conducted by Edmonds, Topalova and Pavcnik (2009), in Yemen, has also revealed that children from poor families are employed in a variety of occupations ranging from street vending to guards in the farms.

The time that children spend in contributing to the household responsibilities, either through work outside or inside the home, will 
negatively affect their ability to stay in school. Previous studies have clearly shown the impact of child labour on children's education. For example in Ethiopia, children combine their work and school attendance because of the financial burden of the family. They also need financial support to pay for the school expenses (Dyer 2007). Duryea and Arends-Kuenning (2003) claim that the time children spend working is associated with school failure in the medium term.

When poverty places high pressure on the family, parents have to take action. They have to go out to either look for food or earn money for their daily survival. In Houa Kham, people search for food in the forest; men go fishing in the lake or in a small river, and women look for mushrooms and bamboo shoots, among other edible items. These activities require a lot of time, they sometimes go in the morning and come back in the afternoon and some people pack some food in case they have to stay a longer time to search for food. As a consequence, there is a need for the child's help or contribution to the family when parents spend time outside of the house. Children from this family will not have enough time to study effectively and sufficiently, which leads to problems at school: they cannot follow what is daily taught in the class and are unable to perform well in their studies. When this happens to students, they lose motivation and confidence in their capacities. Eventually, these children feel bored with homework and other school tasks. They will not have the courage to study and finally drop out of school.

Certain aspects of the school system in Laos present another troubling issue contributing to the problem of school dropouts. First, the current primary school has low quality in terms of its infrastructure and the availability of school facilities, such as chairs, tables, latrine etc. Second, the quality of teaching and learning processes is not sufficient because teachers have low ability in teaching. In addition, the lack of teaching and learning materials also challenges teachers' activity. There are no visual aids to help teachers deliver their knowledge to students effectively. Third, the students' lack of motivation and enthusiasm, which is actually the consequence of the first, second and third factors. Fourth, when students have less motivation to study it results in low performance and frequently in grade repetition. Fifth, students have no hope to continue studying further because there is no secondary school in this village. They tend to foresee what is going to happen to them after they finish the primary level. The parents also do not get involved in children's formal education because they do not see any connection between education and their children's future.

Finally, the gender stereotype where women are weaker than men and not supposed to take the lead also has a damaging effect. This social stereotype has been brought from the old time up to the present and has become part of 
the cultural identity, which makes most women perceive that having a higher level of formal education is not going to be necessary for their future. The opportunities to pursue education that are taken away from them or even by themselves make these women unable to realise how important education is. Therefore, gender stereoty pes have a tremendous impact on women's formal education. As most Buddhist women justify themselves based on their religious beliefs, they conform their social behaviour based on what they learnt from the past generations, when supposedly women had to be obedient and follow the husband. There are some Lao proverbs that actually reflect the gender disparity, and teach women to think in the way they are ${ }^{1}$, 'Husbands are elephant's front feet, wives are the elephant's back feet', and another proverb is: 'Wives should wake up early and go to bed after'. These proverbs come from ancient times, and they give the idea that women should conform to these living standards. However, nowadays people are still practicing the teaching of these two proverbs, as it has been found in this village. This can also constitute an explanation for the inadequate level of education of women and girls from this village.

\section{Conclusion}

Previous literature has revealed a number of factors that influence children's educational attainment. Those factors are poverty, child labour, educational level of parents, educational system and management, and other factors like difficult transportation, school location, etc. In this study, even if these factors were found to be significantly related to issues regarding educational attainment among children in the sampled village, some components and contexts remain distinctive. The findings of my research have directed me to a similar conclusion in the case of Laos.

The economic situation of the families was not found to be the major impact on children's schooling, the household economy and the inability to afford school materials or other indirect costs were not the main factor for school dropout. However, the financial effect on children's schooling could be explained by the fact that in this society (village), money is perceived as the most important possession, which everyone has to work hard for. Because of poverty and together with the low level of education, people think that what money can buy is the most important. People place a high value on money and they also tend to respect those who are richer. In return, they also want to be rich because they want to be respected as well. This situation often results in migration to Thailand, usually among teenagers.

\footnotetext{
1 The proverb is not considered as a law which all people have to strictly obey, but it has some impact on the life of people culturally and socially to some extent.
} 
There are great disparities among those who have access to primary schools in Lao PDR, for example, in the type of school and the quality of the classroom environment, due to the national budget, which limits the ability to provide education to all remote areas. There is a serious shortage of schools and facilities in the undeveloped remote mountainous areas such as the sampled village. This and the fact that most of the schools in rural areas are in temporary construction made with dirt floors, woven bamboo walls, and thatched grass roofs, which place youth at a distinct disadvantage. Other basic facilities such as clean water supply, toilets, furniture, learning materials, including the officially prescribed textbooks and playground are also lacking or in a poor condition. These cumulatively are unattractive to students and teachers who go to school. It is one of the reasons that teachers do not want to teach there and for students to drop out of school before finishing, as the data from the interviews suggested. This study identifies some possible solutions and interventions for future educational development plans and strategies. Education of children in rural areas has to be taken into consideration; girls' education should be prioritised, and immediate actionsshould be taken.

Compared to other factors, I would like to emphasise that the cultural aspect has the most significant impact on school dropout rates among children in this village. People in this village strongly believe in tradition, practice religious ceremonies, and believe that things occur because of ghost power and spirits. Women get involved in the religious ceremony more than the men; it is the responsibility of women to prepare and organise everything for the religious performance.

Also, it has been found that gender inequality is the result of cultural practices; it is the consequence of the social beliefs that women are supposed to be followers of their husbands. These social notions have led to gender stereotypes about roles in the community, which are clearly divided between women and men. Women not only take care of the household chores at home but they also have to prepare religious ceremonies in the community; while men play the role of leader both at home and in the community. The distinction in gender roles made in this village are the justification for women's lack of education and opportunity, and determine the gap in gender education and school dropout among many girls. Therefore, it can be concluded that the dominance over women in a patriarchal society contributes markedly to the gap found in the educational path.

\section{References}

Acemoglu, D. and Pischke, J. (2001) Changes in the wage structure, family income, and children's education. European Economic Review, 45(4-6), 890-904. 
Admassie, Assefa (2003) Child labour and schooling in the context of a subsistence rural economy: can they be compatible? International Journal of Educational Development, 23(2), 167-185.

Dessy, S. and Knowles, J. (2008) Why is child labor illegal? European Economic Review, 52(7), 1275-1311.

Duryea, S. and Arends-Kuenning, M. (2003) School Attendance, Child Labor and Local Labor Market Fluctuations in Urban Brazil. World Development, 31(7), 1165-1178.

Dyer, Caroline (2007) Working children and educational inclusion in Yemen. International Journal of Educational Development, 27(5), 512-524.

Edmonds, E., V. Topalova, P. and Pavcnik, N. (2009) Child labour and schooling in a globalizing world: some evidence from urban India. European Economic Association, 7(2-3), 498-507.

Emerson, P. M. and Souza, A. P. (2008) Birth Order, Child Labor, and School Attendance in Brazil. World Development, 36(9), 1647-1664.

Hammersley, Martyn. (1992) What's Wrong with Ethnography: The Myth of Theoretical Description. In What's Wrong with the Ethnography? Methodological Exploration. London: Routledge.

Hammond, Peter. B. (1978) An Introduction to Social and Cultural Anthropology (2nd ed.). New York: Macmillan Publishing Co., Inc.

Holgado, D., Maya-Jariego, I., Ramos, I., Palacio, J., Oviedo-Trespalacios, Ó., Romero-Mendoza, V. and Amar, J. (2014) Impact of child labor on academic performance: Evidence from the program 'Edúcame Primero Colombia'. International Journal of Educational Development, 34, 58-66.

Jaeger, M. M. and Holm, A. (2007) Does parents' economic, cultural, and social capital explain the social class effect on educational attainment in the Scandinavian mobility regime? Social Science Research, 36(2), 719-744.

Jorgensen, Danny (1989) Participant Observation: A Methodology for Human Studies. California: SAGE Publication Ltd.

Kazianga, Harounan (2012) Income Risk and Household Schooling Decisions in Burkina Faso. World Development, 40(8), 1647-1662.

Kim, Y. (2009) Minority parental involvement and school barriers: Moving the focus away from deficiencies of parents. Educational Research Review, 4(2), 80-102. 
Loken, K. (2010) Family income and children's education: Using the Norwegian oil boom as a natural experiment. Labour Economics, 17(1), 118129.

Mahamood, S. F., Tapsir, R., Saat, A., Ahmad, S., Wahab, K., Boon, M. and Rahman, K. (2012) Parental Attitude and Involvement in Children's Education: A Study on the Parental Aspiration among Form Four Students in Selangor. Procedia - Social and Behavioral Sciences, 42(July 2010), 117-130.

Miedel, W. and Reynolds, A. (2000) Parent Involvement in Early Intervention for Disadvantaged Children: Does It Matter? Journal of School Psychology, 37(4), 379-402.

Nguon, Sokcheng (2012) Parental involvement and students' achievement in Cambodia: Focusing on parental resourcing of public schooling. International Journal of Educational Research, 53, 213-224.

Oketch, M., Mutisya, M., And Sagwe, J. (2012) Parental aspirations for their children's educational attainment and the realisation of universal primary education (UPE) in Kenya: Evidence from slum and non-slum residences. International Journal of Educational Development, 32(6), 764-772.

Shapiro, D. and Oleko T., (2001) Gender, poverty, family structure, and investments in children's education in Kinshasa, Congo. Economics of Education Review, 20(4), 359-375.

Sheng, Xing (2012) Cultural capital and gender differences in parental involvement in children's schooling and higher education choice in China. Gender and Education, 24(2), 131-146.

Spradley, James (1979) The Ethnographic Interview. United States of America: Wadsworth Publishing Co Inc.

Stephens, D (2000) Girls and basic education in Ghana: a cultural enquiry. International Journal of Educational Development, 20, 29-47.

Taylor, Stephanie (2002) Ethnographic research: A Reader. London: SAGE Publication Ltd.

Webbink, E., Smits, J. and De Jong, E. (2012) Hidden Child Labor: Determinants of Housework and Family Business Work of Children in 16 Developing Countries. World Development, 40(3), 631-642.

World Bank (2007) Global Monitoring Report 2007. Washington DC: The International Bank for Reconstruction and Development / The World Bank. 